\title{
A EXPERIÊNCIA DO DESIGNER NO PROCESSO DE COEVOLUÇÃO DO PROBLEMA DE DESIGN
}

Débora de Oliveira Lemos Rocha de Souza

UNISINOS

deboraolrs@gmail.com

Guilherme Corrêa Meyer

UNISINOS

gcmeyer@unisinos.br

Resumo: Este artigo parte de uma pesquisa interessada em avançar na compreensão de aspectos da coevolução do problema de design. Mais especificamente, debruça-se sobre a relação entre as experiências do designer e tal processo coevolutivo. Um estudo exploratório foi elaborado a partir de um workshop de design. Uma série de grupos focais intercalaram-se de forma a abranger o modo como transcorria a compreensão dos participantes sobre o problema proposto e a relação com eventuais ideias de solução. A análise dos grupos focais foi orientada pelo método de Análise de Conteúdo. As categorias surgiram indutivamente, mas também pautadas nos episódios de coevolução revelados. Participaram do workshop diversos designers com experiências variadas. Dentre as constatações da pesquisa, identificou-se que alguns dos fatores que influenciam o processo de coevolução tem ligação com as heurísticas que o designer aciona durante o curso do projeto. Mais precisamente, identificou-se que (1) a bagagem do designer influencia a formulação inicial do problema; (2) tal bagagem influencia a percepção de dificuldade em tratar o problema; (3) os líderes com mais experiência influenciam o processo de forma particular.

Palavras-chave: coevolução; problema de design; experiência do designer.

\begin{abstract}
This article is aimed at understanding some aspects of the design problem coevolution. More specifically, it focuses on the relationship between the experiences of the designer and this co-evolutionary process. An exploratory study was drawn from a design workshop. A series of focus groups was held in order to cover the way the participants have been understood the proposed problem and the relationship with possible solution ideas. The analysis of the focus groups was guided by the content analysis method. The categories have emerged inductively but also have guided by the coevolution episodes. The workshop involved several designers from various backgrounds. Among the findings of the research, it was found that some of the factors that influence the coevolution process
\end{abstract}


were connected with the heuristics that the designer triggers during the project. More precisely, it was found that (1) the designer's experience influences the initial formulation of the problem; (2) such experience influences the perception of difficulty in dealing with the problem; (3) the leaders with more experience influence particularly the design process.

Keywords: coevolution; design problem, designer experience.

\section{INTRODUÇÃO}

Este artigo surge de uma pesquisa realizada entre 2014-2015 que buscou compreender a coevolução do problema de design. Dentre algumas das constatações da pesquisa, identificou-se que alguns dos fatores que influenciam o processo de coevolução tem ligação com as heurísticas (da disponibilidade) que o designer aciona durante o curso do projeto. 0 conceito de heurística pode ser descrito aqui como o conjunto de influências gerais utilizadas pelos indivíduos para tomar decisões sobre o indeterminado (TVERSKY; KAHNEMAN, 1974). As heurísticas da disponibilidade explicam que o indivíduo tende a avaliar tais circunstâncias baseado na facilidade com que acessam suas memórias (TONETTO; TAMMINEN, 2016). Neste artigo, descreve-se a relação de um componente de disponibilidade a que o designer recorre ao envolverse no processo de coevolução: a experiência anterior de que faz uso o profissional.

Parte dessas experiências é composta de informações de projetos anteriores, vivências do cotidiano e aspectos da individualidade do designer, tais como ideais, posicionamentos e formas de interpretar a realidade. Utiliza-se aqui a metáfora da bagagem para representar todas essas informações, de âmbito profissional e pessoal, que o designer utiliza no seu processo de formulação e resolução dos problemas.

Essa bagagem caracteriza-se por um importante conhecimento, tanto para os profissionais como para as organizações, pois, à medida que se compreende melhor essa influência, torna-se possível montar estratégias para tornar esse conhecimento mais acessível aos diferentes atores envolvidos no projeto. $O$ elemento da acessibilidade revela-se aspecto importante durante o processo de coevolução que será aqui apresentado.

Dessa forma, o objetivo deste artigo é refletir sobre os aspectos relacionados à bagagem (experiências anteriores ao projeto) do designer que influenciam o processo de coevolução no design.

Para isso, apresenta-se o conceito de coevolução que evidencia em que perspectiva teórica aborda-se o processo de design, mostrando o ponto de partida desta pesquisa. Em seguida, descreve-se o método, expõem-se e analisam-se os resultados.

\section{ASPECTOS DO PROCESSO DE DESIGN, COEVOLUÇÃO E O MECANISMOS DAS HEURÍSTICAS}

Para falar sobre o processo de design, mesmo que rapidamente, como será realizado neste tópico, é necessário considerar a natureza dos problemas de design. Rittel e Webber (1973) utilizaram a expressão "wicked problems" para mostrar que alguns problemas possuem propriedades distintas dos problemas bem definidos. Esses problemas são caracterizados como "perversos (wicked)", complicados, porque não se 
apresentam de forma clara. Essa natureza "wicked" dos problemas de design requer dos designers a utilização de referências anteriores, que muitas vezes são acionadas sem que sejam pelas vias da racionalidade. Tal procedimento pode ser pensado pela ótica das heurísticas. Procurar-se-á discutir mais adiante que tal recurso não é facultativo ao designer; ou seja, ou bem o designer o aciona, ou não consegue avançar nas decisões que precisa recorrer durante o processo de coevolução de sua atividade.

A heurística é utilizada no momento em que o cérebro não encontra uma resposta para uma questão difícil e automaticamente constrói outra questão mais simples para conseguir alguma resposta. A heurística da disponibilidade relaciona-se à ação de construir julgamentos, percepções, baseados na facilidade com que se consegue resgatar algumas informações da memória. Apesar de a heurística ser uma estratégia necessária para solucionar problemas complexos, em algumas situações, poderá conduzir a uma resposta tendenciosa porque se constrói um questionamento mais simples para responder a algo mais complexo (KAHNEMAN, 2012).

A heurística da disponibilidade relaciona-se ao conceito de coevolução, pois o designer utiliza diversas informações da sua bagagem para lidar com a complexidade dos problemas, criando questões sucessivas que o levarão a compreender melhor o problema e a vislumbrar diferentes soluções. O conceito de coevolução percebe a resolução de problemas de forma evolutiva: à medida que se compreende um pouco mais o problema, as respostas tornam-se mais aprimoradas.

Esse conceito de coevolução é usado por Poon e Maher (1997) que utilizam o conceito de coevolução biológica para explicar o processo de resolução de problema no design. A principal contribuição dos autores é mostrar que o espaço-problema e o espaço-solução interagem e se modificam no decorrer do projeto de forma a provocar uma evolução mútua (POON; MAHER, 1997), o que pode ser visualizado no modelo abaixo (Figura 1):

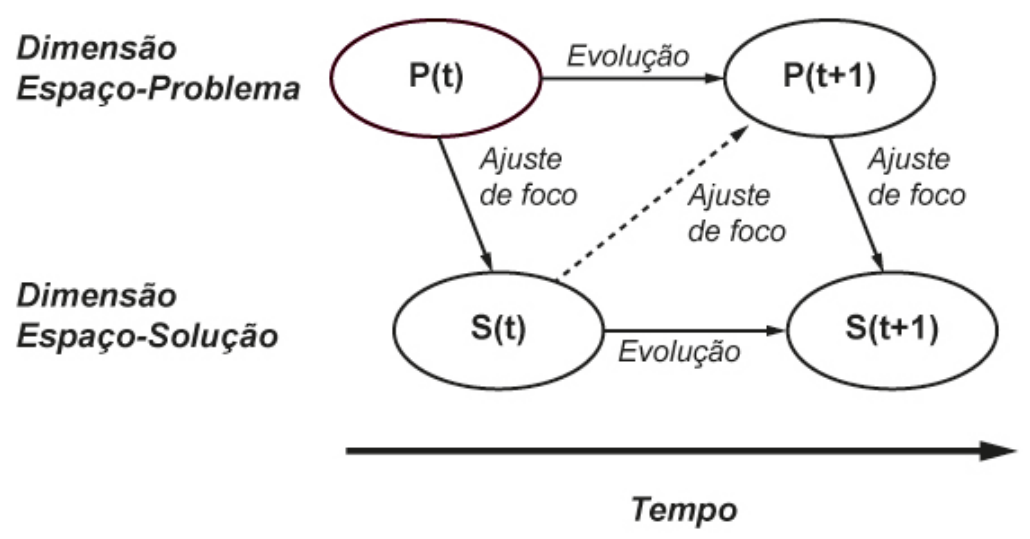

Figura 1 - Modelo de coevolução do problema-solução de Maher e Poon Fonte: (POON; MAHER, 1997)

Quando a formulação atual do problema $(\mathrm{P}(\mathrm{t}))$ não oferece subsídios para encontrar uma solução $(\mathrm{S}(\mathrm{t}))$, o espaço-solução é utilizado para ajustar o foco do espaço-problema (linha diagonal tracejada). Esse espaço-problema modificado com novos requisitos $(P(t+1)$ ) ajusta o foco do espaço-solução $(S(t+1)$ ). (MAHER; TANG, 2003) (POON; MAHER,1997). Assim, o espaço-problema caracteriza-se pelas sucessivas reformulações do problema durante o projeto. De forma semelhante, o espaço- 
solução é marcado por todas as soluções encontradas (inclusive, as rejeitadas) que foram sendo adaptadas aos novos requisitos do problema (MAHER; TANG, 2003).

Dorst e Cross (2001), validam o modelo de coevolução proposto por Maher ao relacioná-lo com o design criativo. 0 modelo abaixo (Figura 6) apresenta o processo de coevolução constatado na pesquisa dos autores:

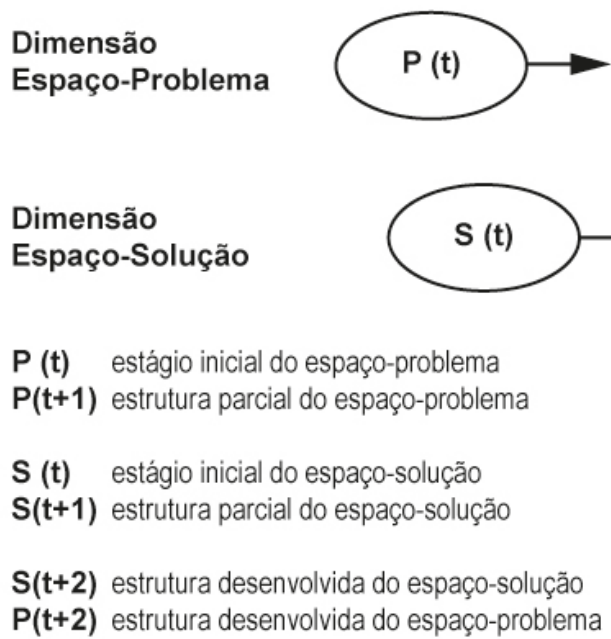

Figura 2 - Modelo de coevolução do problema-solução de Dorst e Cross Fonte: (DORST; CROSS, 2001, p 435).

Dorst e Cross explicam o modelo de coevolução da seguinte forma:

\begin{abstract}
Os designers começam explorando o espaço-problema, e encontram, descobrem, ou reconhecem uma estrutura parcial $(P(t+1))$. Essa estrutura parcial é então utilizada como subsídio para uma estruturação parcial do espaço-solução $(S(t+1))$. Os designers consideram as implicações da estruturação parcial do espaço-solução, e à utilizam para gerar algumas idéias iniciais que formam um conceito de design, e assim ampliam e desenvolvem a estruturação parcial $(S(t+2))$. Parte desse desenvolvimento da estruturação parcial pode surgir de referências de projetos anteriores de design. Eles transferem a estrutura desenvolvida da solução parcial de volta para o espaço-problema $(P(t+2))$, e novamente consideram as implicações e estendem a estruturação do espaço-problema. O objetivo é criar um par de problema-solução correspondente (DORST; CROSS, 2001, p. 434-435).
\end{abstract}

Segundo os autores, o design criativo não consiste em corrigir o problema que inicialmente se apresenta de forma mal-estruturada, mas em aperfeiçoar a formulação do problema e as ideias para a solução, construindo uma ponte entre o "espaçoproblema" e o "espaço-solução". Isso exige um tempo de exploração para desencadear a evolução de ambos os espaços até que a conexão seja estabelecida, geralmente, pela identificação de um conceito-chave (DORST; CROSS, 2001) (DORST; 2006).

A representação do tempo no modelo de coevolução representado por Poon e Maher ocorre na forma de uma linha reta. No entanto, Souza (2015) apresenta o modelo em forma de espiral (Figura 3) e o incrementa com uma linha pontilhada (que se encontra no centro da espiral) com a finalidade de também representar as experiências profissionais e pessoais que o designer traz para o projeto. 


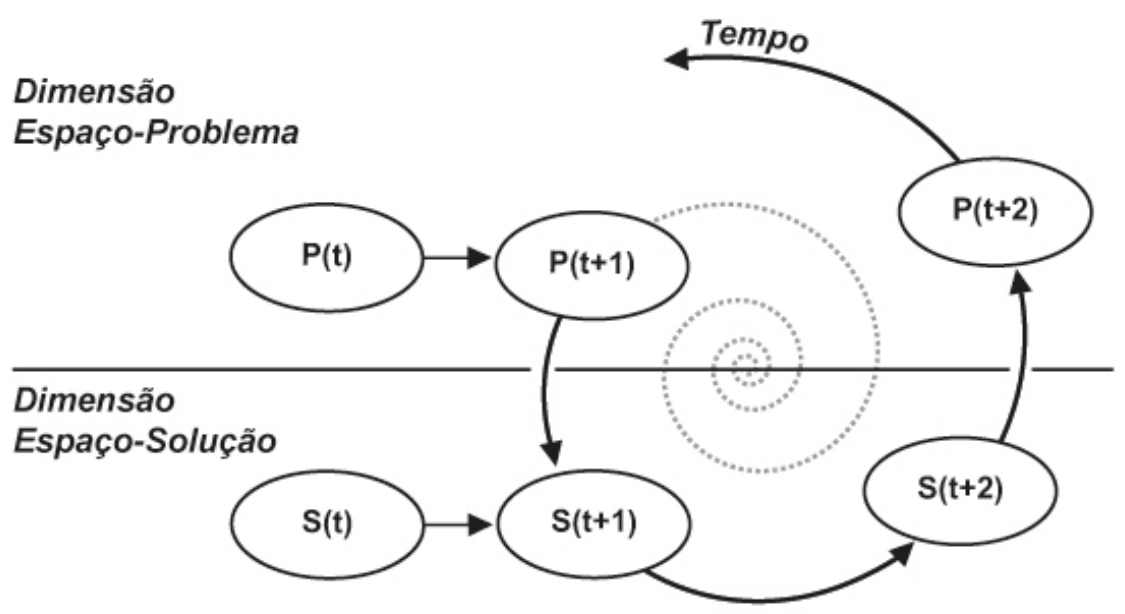

Figura 3 - Modelo de coevolução ajustado à pesquisa realizada Fonte: (SOUZA, 2015).

Utilizando como principal referência Dorst e Cross (2001), a explicação do modelo em espiral proposto é a seguinte: os designers constroem uma formulação inicial do problema $(P(t+1))$ que é utilizada para conceber as primeiras ideias de soluções $(S(t+1))$. À medida que os designers conseguem estruturar melhor essas ideias de soluções, eles evoluem no processo de forma que essas possíveis soluções compõem - ou se aproximam de - um conceito de design ( $S(t+2)$ ). Isso modifica a forma como os designers percebem o problema $(P(t+2))$, podendo desencadear uma nova formulação do problema que, consequentemente, pode alterar as possíveis soluções. Importante referir, ainda, que o problema pode-se modificar diversas vezes dentro do espaço-problema e só depois alterar o espaço-solução. Igualmente, a solução pode se modificar várias vezes dentro do espaço-solução e só depois modificar o espaço-problema gerando uma nova formulação do problema. Essa evolução no espaço-problema e no espaço-solução pode ocorrer diversas vezes durante o projeto até se criar um par ajustado de problema-solução.

Nesse modelo de coevolução, a linha do tempo é representada inicialmente por uma linha pontilhada (que se encontra no centro da espiral), tentando representar as experiências profissionais e pessoais do designer que influenciam na formulação inicial do problema. Isso por que entende-se que o primeiro contato do designer com o problema, por exemplo, quando escuta o briefing e o compreende de alguma forma, já se caracteriza por sua primeira formulação do problema. Essa bagagem (experiências, habilidades, etc.) que o designer traz para o projeto, influencia nas diversas transformações do problema e da solução durante todo o processo.

As representações $(P(t))$ e $(S(t))$ caracterizam-se pelo problema malestruturado sem a ação do designer. Por exemplo, o problema apresentado por um cliente pode ter uma formulação do problema e o que ele imagina (ou espera) como solução. Mas, no decorrer do projeto, isso será modificado de alguma forma, o que é representado por $(P(t+1)),(S(t+1)) \ldots$

Como uma forma de identificar os episódios de coevolução, Maher e Tang (2003) definiram que as possíveis soluções encontradas no decorrer do projeto, geralmente, são acompanhadas por mudanças de requisitos em relação ao problema. Os autores identificaram quatro tipos de ações dos designers que podem modificar os requisitos do problema de forma imediata ou ao longo do processo: 1) Adição de 
novos requisitos ao problema $\left.\left(A D D^{1}\right) ; 2\right)$ Refinamento dos requisitos do problema (REF); 3) Busca por novos requisitos para o problema (SEA); 4) Reavaliação dos requisitos do problema (REE). As soluções, geralmente, são alteradas quando há: 1) Pensamentos de soluções (THO); 2) Desenhos de soluções (DRA); 3) Exame de soluções (EXA).

Examinadas as importâncias dos episódios do processo de coevolução no design, bem como algumas de suas disposições gerais, descreve-se agora a maneira como foi conduzida esta pesquisa, de forma que se alcançasse uma compreensão da relação entre a bagagem dos profissionais de design e o processo de coevolução.

\section{MÉTODO}

Para atender aos objetivos desta pesquisa exploratória, realizou-se um workshop em design. O workshop teve a duração de um dia e contou com a participação de oito profissionais com especialidades variadas. O principal critério para a seleção desses participantes foi a experiência profissional, buscando assegurar que estariam acostumados a solucionar problemas semelhantes ao que foi apresentado. Eles foram divididos em duas equipes de trabalho, mantendo um equilíbrio em relação às especialidades e ao tempo de experiência.

Considerando a relevância do problema de design para esta pesquisa, construiu-se cinco briefings com abordagens diferentes e solicitou-se a cinco professores da área de projeto que julgassem o briefing mais apropriado de acordo com os seguintes critérios: o problema deve ser de "baixa complexidade" e "wicked". Segundo Dorst (1996) problema de baixa complexidade é: 1. desafiador; 2. realista; 3. apropriado ao tema abordado; 4. não muito grande; 5 . possível no tempo disponível; 6. dentro da esfera do conhecimento de designers. Para Rittel e Webber (1973), o problema "wicked" não se apresenta de forma definida, compreensível e consensual, de forma que pode ser visto de diferentes perspectivas, possibilitando diferentes respostas.

Dessa forma, o briefing escolhido e apresentado aos participantes foi o "Horta Criativa". Esse briefing contextualizava uma cidade em crescimento em que a prefeitura promovia algumas ações para resgatar o hábito dos moradores de cultivar uma horta. Aos designers foi solicitado criar um sistema produto-serviço que estimulasse esse hábito.

Os participantes tiveram 3h40min de trabalho para atender ao briefing proposto. Esse tempo foi dividido em dois momentos de trabalho, o primeiro com $2 \mathrm{~h}$ e o segundo com 1h40min. Na primeira parte, incentivou-se os participantes a buscar estímulos criativos, a realizar um brainstorming, a construir mapas conceituais, a identificar forças motoras e a construir cenários. Na segunda parte, eles foram incentivados a descrever os cenários e a identificar os conceitos que norteariam as soluções por eles propostas. Essas etapas fizeram parte da dinâmica do processo de projeto de ambas as equipes.

\footnotetext{
ADD - Adding new problem requirements, REF - Refining problem requirements, SEA - Searching solutions, DRA - Drawings of solutions, EXA - Examining the solutions.
} 
A estrutura do workshop foi planejada de forma que possibilitasse a realização de três grupos focais com cada uma das equipes e permitisse a observação dos grupos quando estivessem trabalhando.

Para cada grupo focal, foi preparado um roteiro com três perguntas centrais acompanhadas com perguntas de apoio. As questões, de modo geral, buscavam perceber: 1) Como os participantes se sentiam em relação ao problema no decorrer do projeto. 2) Como compreenderam o problema no início do projeto e como esse entendimento se modificava à medida que tentavam resolvê-lo. 3) Quais as soluções encontradas e como elas surgiram na dinâmica do processo de projeto.

Os grupos focais permitiram aos participantes expressarem diferentes pontos de vistas e evidenciarem a forma como perceberam o processo de resolução do problema proposto. Os grupos focais foram realizados no local em que cada grupo desenvolveu o projeto, pois, à medida que o projeto foi desenvolvido, esse ambiente tornou-se mais familiar para todos os participantes. Além disso, a proximidade com os esboços e desenhos contribuiu para alguns participantes apresentarem suas percepções de forma mais precisa.

A observação foi realizada no momento em que os grupos estavam trabalhando e também posteriormente, pois todo o processo de projeto realizado pelos grupos foi gravado em vídeos. Os aspectos observados foram: 1) a forma como os participantes se articulavam no grupo para solucionar o problema proposto; e 2) o processo realizado pelos participantes para formular o problema e encontrar possíveis soluções.

A interpretação dos materiais coletados foi feita mediante a técnica de análise de conteúdo (MORAES, 1999; BARDIN, 2011). Todos os materiais foram exaustivamente apreciados indutivamente, seguindo os preceitos de análise propostos pelo método escolhido. Assim, após transcritas as entrevistas, os grupos focais e as falas registradas durante a observação do exercício, foram realizadas as tarefas de preparação das informações, transformação do conteúdo em unidades, categorização, descrição e interpretação.

\section{APRESENTAÇÃO DOS RESULTADOS}

Neste tópico, apresenta-se o perfil dos participantes (Quadro 1) e a descrição das categorias e subcategorias (Quadro 2) identificadas nas transcrições dos grupos focais pela técnica análise de conteúdo. 
Quadro 1 - Perfil dos participantes do workshop

\begin{tabular}{|c|c|c|c|c|c|}
\hline \multicolumn{6}{|c|}{ PERFIL DOS PARTICIPANTES } \\
\hline & & $\begin{array}{l}\text { 1) Nível superior e } \\
\text { o ano de conclusão } \\
\text { do curso: }\end{array}$ & $\begin{array}{l}\text { 2) Tempo de } \\
\text { atuação } \\
\text { profissional: }\end{array}$ & $\begin{array}{l}\text { 3) Relação atual com } \\
\text { o design: }\end{array}$ & 4) Função atual: \\
\hline \multirow{4}{*}{ 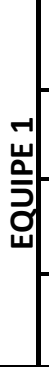 } & Informante 1 & $\begin{array}{l}\text { Design de Produto } \\
\text { (1993) }\end{array}$ & 22 anos & Design de Produto & $\begin{array}{l}\text { Coordenador de } \\
\text { Design }\end{array}$ \\
\hline & Informante 2 & $\begin{array}{l}\text { Publicidade e } \\
\text { Propaganda (2013) }\end{array}$ & 8 anos & Design Gráfico & $\begin{array}{l}\text { Analista de } \\
\text { Criação }\end{array}$ \\
\hline & Informante 3 & - & 15 anos & Design Gráfico & $\begin{array}{l}\text { Diretor de Criação } \\
\& \text { Planejamento }\end{array}$ \\
\hline & Informante 4 & $\begin{array}{l}\text { Design de Moda } \\
(2010)\end{array}$ & 7 anos & Design de Moda & Criação \\
\hline \multirow{4}{*}{ 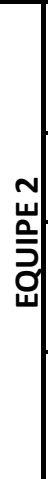 } & Informante 5 & $\begin{array}{l}\text { Comunicação Visual } \\
\text { (1987) }\end{array}$ & 30 anos & $\begin{array}{l}\text { Publicidade, } \\
\text { Programação Visual e } \\
\text { Editoração de livros. }\end{array}$ & $\begin{array}{l}\text { Designer Gráfico } \\
\text { e Artista Plástico. }\end{array}$ \\
\hline & Informante 6 & $\begin{array}{l}\text { Arquitetura e } \\
\text { Urbanismo (2005) }\end{array}$ & 10 anos & $\begin{array}{l}\text { Design de Interiores, } \\
\text { Produto e Gráfico }\end{array}$ & Arquiteto \\
\hline & Informante 7 & $\begin{array}{l}\text { Design de Moda } \\
(1998)\end{array}$ & 18 anos & $\begin{array}{l}\text { Design de Moda e } \\
\text { Design de Produto }\end{array}$ & Consultora \\
\hline & Informante 8 & Design (2006) & 9 anos & $\begin{array}{l}\text { Design de Produto, } \\
\text { Comunicação e } \\
\text { Design de Serviço. }\end{array}$ & $\begin{array}{l}\text { Professor do } \\
\text { Curso de Design } \\
\text { de Produto }\end{array}$ \\
\hline
\end{tabular}

Fonte: Elaborado pelos autores, com base na pesquisa realizada.

$\mathrm{Na}$ análise do conteúdo dos grupos focais, identificaram-se três categorias: 1) Sentimentos; 2) Articulações de Equipe; e 3) Problema e Solução. Segue, abaixo, a apresentação das categorias e subcategorias encontradas.

\section{Quadro 2 - Descrição das Categorias dos Grupos Focais}

\begin{tabular}{|c|c|}
\hline CATEGORIAS & SUBCATEGORIAS \\
\hline \multirow{3}{*}{$\begin{array}{l}\text { 1) Sentimentos: } \\
\text { A categoria sentimentos } \\
\text { refere-se às emoções } \\
\text { mencionadas pelos } \\
\text { participantes no decorrer } \\
\text { do processo. }\end{array}$} & $\begin{array}{l}1.1 \text { - Envolvimento - Representa alguns sentimentos que sinalizam o } \\
\text { envolvimento do designer com o problema proposto. }\end{array}$ \\
\hline & $\begin{array}{l}1.2 \text { - Nível de dificuldade - Alguns sentimentos estão relacionados à } \\
\text { percepção que o designer constrói sobre o nível de dificuldade do } \\
\text { problema. }\end{array}$ \\
\hline & $\begin{array}{l}1.3 \text { - Evolução dos sentimentos - Os sentimentos se modificam ao longo } \\
\text { do processo à medida que o problema é solucionado. }\end{array}$ \\
\hline \multirow{4}{*}{$\begin{array}{l}\text { 2) Articulações de Equipe: } \\
\text { identificou-se a forma } \\
\text { como os participantes se } \\
\text { articularam no grupo e } \\
\text { como isso influenciou na } \\
\text { maneira de trabalharem e } \\
\text { de perceberem o } \\
\text { problema. Tais } \\
\text { informações dividem-se } \\
\text { nas seguintes } \\
\text { subcategorias: }\end{array}$} & $\begin{array}{l}2.1 \text { - O meu jeito de fazer - Quando perguntados sobre o processo } \\
\text { percorrido, os participantes revelam a maneira pessoal de agir para } \\
\text { solucionar os problemas de design. }\end{array}$ \\
\hline & $\begin{array}{l}2.2 \text { - Pela minha experiência - Essa subcategoria apresenta as } \\
\text { convicções dos designers sobre o processo criativo, muitas delas com } \\
\text { origem nas experiências profissionais e pessoais. }\end{array}$ \\
\hline & $\begin{array}{l}2.3 \text { - Convenções do grupo - À medida que os participantes falam sobre } \\
\text { o processo criativo, alguns posicionamentos funcionam como } \\
\text { convenções temporárias para o grupo funcionar. }\end{array}$ \\
\hline & $\begin{array}{l}2.4 \text { - Percepções dos papéis - Refere-se à identificação que os } \\
\text { participantes fazem das contribuições de cada integrante do grupo } \\
\text { relacionando com a formação, ou percebendo que as ideias se } \\
\text { complementam. }\end{array}$ \\
\hline
\end{tabular}




\begin{tabular}{|c|c|}
\hline \multirow{6}{*}{$\begin{array}{l}\text { 3) Problema e Solução: } \\
\text { Nessa categoria estão seis } \\
\text { subcategorias que } \\
\text { apresentam os momentos } \\
\text { em que os participantes se } \\
\text { referem ao problema e/ou } \\
\text { à solução. As } \\
\text { subcategorias } \\
\text { identificadas são: }\end{array}$} & $\begin{array}{l}\text { 3.1 - Simultaneidade entre Problema e Solução - Refere-se às falas em } \\
\text { que os participantes revelam que, ao receber o briefing, imediatamente } \\
\text { começam a ter diversas ideias. }\end{array}$ \\
\hline & $\begin{array}{l}\text { 3.2 - Características dos problemas mal-estruturados - Surge a partir da } \\
\text { discussão de Rittel e Webber (1973) sobre as características dos } \\
\text { problemas mal-estruturados. Desse modo, parte-se das características } \\
\text { mencionadas pelo autor. }\end{array}$ \\
\hline & $\begin{array}{l}\text { 3.3 - Formulação do problema - Refere-se às falas em que cada uma das } \\
\text { equipes revela como compreendeu o problema e foi aprimorando essa } \\
\text { compreensão ao longo do processo. }\end{array}$ \\
\hline & $\begin{array}{l}\text { 3.4 - Questionamentos em relação ao problema ou à solução - Essa } \\
\text { subcategoria se ateve aos questionamentos que os informantes faziam } \\
\text { em relação ao problema quando descreviam o processo. }\end{array}$ \\
\hline & $\begin{array}{l}\text { 3.5 - Ferramentas e suas contribuições - Refere-se às falas em que os } \\
\text { participantes reconhecem as contribuições das ferramentas utilizadas. }\end{array}$ \\
\hline & $\begin{array}{l}\text { 3.6 - Possíveis soluções - Refere-se às possíveis soluções mencionadas } \\
\text { pelos participantes desde os primeiros insights até a proposta } \\
\text { apresentada no final. Isso pode ajudar a perceber o aprimoramento que } \\
\text { as soluções tiveram ao longo do processo. }\end{array}$ \\
\hline
\end{tabular}

Fonte: Elaborado pelos autores, com base na pesquisa realizada.

Alguns dos aspectos relacionados às experiências que o designer traz para o projeto surgem nessas categorias e se evidenciam no processo observado. No próximo tópico, são apresentados e discutidos esses aspectos. Optou-se por não apresentar na seção de resultados as unidades de análise que formaram as categorias e subcategorias devido à extensão restrita do artigo. Algumas dessas unidades são mencionadas na seção seguinte, em que foram construídos os tópicos de discussão.

\section{DISCUSSÃO DOS RESULTADOS}

\subsection{A bagagem influencia a percepção do nível de dificuldade do problema}

A influência da bagagem já se evidencia no início do processo quando o designer passa a conhecer o problema e, de forma quase simultânea, começa a ter ideias de soluções (subcategoria 3.1, quadro 2). Isso pode ser percebido na fala do informante 1 "Na minha cabeça já surgiram várias ideias, umas eu já descartei, isso não, isso sim, isso não...".

A facilidade ou não em gerar essas primeiras ideias, talvez já acompanhadas de uma avaliação inicial, leva o designer a construir uma percepção do nível de dificuldade do problema. $O$ informante 1 evidencia isso ao expressar: "tema desafiador (...) um pouco distante do meu dia-a-dia". Essa percepção de dificuldade é construída por um processo heurístico de disponibilidade em que se constrói um julgamento "pela facilidade com que os casos ou ocorrências podem ser trazidos à mente" (TVERSKY; KAHNEMAN, 1974, p. 1127).

Essa percepção do designer sobre o nível de dificuldade do problema pode influenciar no envolvimento dos profissionais com o problema proposto. 0 envolvimento do designer com o problema (subcategoria 1.1, quadro 2) é um dos fatores essenciais para o êxito do projeto. Na equipe 1 , observou-se que os informantes 2 e 3 não estabeleciam um envolvimento constante com o problema, talvez, resultado dessa percepção do nível de dificuldade do problema aliado a um contexto diferente do que estão acostumados. 
A percepção sobre o nível de dificuldade do problema também é construída pelo entrosamento da equipe e pela familiaridade com a dinâmica do trabalho. Por exemplo, o informante 5 expressa a dificuldade de resolver o problema com uma equipe em que há pouca familiaridade entre os participantes: "o maior desafio não foi o briefing, foi eu ter que resolver isso com três pessoas que eu não conheço...". Para o informante 3 , a dificuldade maior foi ter que resolver o problema na conjuntura apresentada no workshop com diversas atividades propostas como estímulos (por exemplo, forças motoras) que não faziam parte de sua bagagem.

\subsection{A bagagem influencia a formulação inicial do problema}

Essas primeiras ideias, em que o designer constrói a percepção sobre a dificuldade do problema, caracteriza-se pela formulação inicial do problema. Observase que as primeiras formulações dos participantes caracterizaram-se por ideias formuladas de forma individual e se aproximam da atuação profissional dos participantes. Por exemplo, o informante 5 começa o processo estimulando a equipe 2 a desenvolver uma marca, algo que ele está acostumado em sua atuação profissional. O informante 6, interage nessa construção inicial da marca, mas investe tempo em desenhar uma das suas primeiras ideias que ele mencionou no grupo focal: "a Praça Dante [praça localizada no centro de Caxias do Sul] como uma grande horta e as pessoas indo lá no sábado, colhendo no seu $\mathrm{m}^{2}$, os seus legumes, vegetais, enfim, o que plantou". Isso se caracteriza por uma intervenção urbana, algo próximo à sua formação em arquitetura.

Pensando na afirmação de Rittel e Webber (1973) de que cada problema é único, parece que quando o problema entra em contato com essa bagagem do designer, estabelece-se a ligação com aquilo que for mais próximo, podendo ser a formulação do problema ou ideias de soluções. No entanto, essa formulação inicial do problema se aproxima da atuação do designer porque ele consegue acessar rapidamente essa vivência, que pode ser caracterizada como uma prática prolongada que o cérebro consegue acessar de forma intuitiva e com pouco ou nenhum esforço (KAHNEMAN, 2012). De acordo com Tonetto e Tamminen (2016), os designers tendem a utilizar a intuição quando não possuem informações concretas sobre um problema de design.

Essa formulação inicial do problema caracteriza-se por uma força impulsionadora, em que o designer se utiliza de um processo heurístico (KAHNEMAN, 2012) para construir uma compreensão, ainda que prematura, do problema para gerar soluções de forma rápida. Por exemplo: o briefing não solicita a criação específica de uma marca, mas o informante 5 utiliza isso como uma tática para desencadear logo a solução do problema.

\subsection{Os líderes tinham maior bagagem e influenciaram mais o processo}

Em cada uma das equipes, o integrante que influenciou mais o processo de design foi aquele que tinha maior experiência profissional. De tal forma que o modo de funcionar da equipe seguiu muito a dinâmica das experiências profissionais (subcategoria 2.2) e o jeito de fazer (subcategoria 2.1) desse integrante.

Em relação às experiências profissionais (subcategoria 2.2 "pela minha experiência"), o informante 1 desempenhou o papel de líder e conduziu a equipe de forma intencional a uma linha de raciocínio de exploração do espaço-problema. Essa 
constante exploração do espaço-problema relaciona-se à sua formação em design em que há uma cultura de projeto que estimula a definição do problema no início do processo. Além disso, ele trabalha há 22 anos como designer de produto e a sua função atual é de coordenador de design, o que pode influenciar no tempo em que ele se dedica à formulação do problema.

O informante 1 também impulsionou todos os episódios de coevolução. Nesse aspecto, assemelha-se à pesquisa realizada por Wiltschnig et. al. (2013) em que também observaram que os episódios de coevolução eram desencadeados por novos requisitos, geralmente, introduzidos pelo líder da equipe. Além disso, de todos os participantes do workshop, o informante 1 foi o que demonstrou maior domínio sobre as ferramentas propostas, de tal forma que adaptou as atividades para desenvolver essa exploração do espaço-problema seguindo a sua linha de raciocínio. Segundo Schön (2000), isso pode ser caracterizado como conhecer-na-ação em que se desenvolve uma determinada habilidade e passa-se a desenvolvê-la de forma natural, assim como a ação de caminhar ou andar de bicicleta.

Além disso, observou-se no informante 1 as características de profissionais proficientes mencionadas por Dorst (2003) que percebem rapidamente as questões relevantes e o plano adequado para atender ao problema. Isso fica evidente na fala do informante 1: "Na verdade, como a gente já é experiente a gente está cortando caminhos".

Em relação à equipe 2, a influência da experiência profissional do informante 5 relaciona-se à sua grande vivência em agência de propaganda em que pode existir uma pressão para se construir campanhas completas em períodos de tempo muito curto e, talvez, o fato de ele também ser artista plástico. Ele, no início do processo, direcionou a equipe a explorar mais o espaço-solução sugerindo a criação de uma marca.

Em relação ao nível de especialização mencionado por Dorst (2003), observa-se no informante 5 as características dos experts que respondem a questões específicas de forma intuitiva. Isso ficou evidente quando a equipe estava desenvolvendo a construção de cenários e ele fez a seguinte afirmação: "Cara, quer ver onde nós vamos chegar? Aqui." e aponta para as soluções formuladas no início do processo.

Essas características profissionais dos informantes 1 e 5, proficiente e expert, evidenciam que a competência aprimorada de solucionar problema é o que legitima, no contexto profissional, o desempenho do papel de liderança. Segundo Meyer (2010), em escritórios de design, o papel de liderança não está atrelado somente a um cargo de chefia, mas ao reconhecimento do grupo em perceber a habilidade de ter boas ideias e saber concretizá-las. Essa habilidade refere-se a uma grande desenvoltura em solucionar problemas difíceis, podendo ser considerada como genialidade.

\section{CONCLUSÃO}

O processo de design, e mais especificamente a maneira como o designer lida com as nuances de sua atividade projetual, guarda aspectos de ordem técnica e social, que não podem ser encerrados numa descrição ligeira. Tal compreensão, alcançada durante a pesquisa como um todo, conduziu a um recorte necessário. Optou-se por tomar, assim, alguns dos aspectos da atividade projetual e verificar a forma como tais aspectos se manifestam em um processo de coevolução. Percebeu-se, assim, que a carga de referências a qual o designer acessa durante o projeto afeta de diversas formas o processo de coevolução. Em suas manifestações mais específicas, identificou- 
se que (1) a bagagem influencia a percepção do nível de dificuldade do problema; (2) a bagagem influencia a formulação inicial do problema e; (3) os líderes tinham maior bagagem e influenciaram mais o processo.

O termo bagagem não deve ser confundido aqui com o conceito de heurísticas, anteriormente apresentado. As bagagens referem-se ao material acessado e não aos mecanismos de acionamento ou à forma como ele é acessado. Acredita-se que a qualidade das bagagens que o designer dispõe interfere decisivamente a possibilidade de prosperar nos projetos por meio das heurísticas. Tal concepção sugere a continuidade deste estudo e outras pesquisas que dele decorram.

\section{REFERÊNCIAS}

BARDIN, L. Análise de Conteúdo. São Paulo: Edições 70, 2011.

CROSS, N.G. (ed.). Developments in Design Methodology. Wiley: Chichester, 1984.

DORST, Kees; CROSS, Nigel. Creativity in the design process: Co-evolution of problemsolution. Design Studies, vol. 22, p. 425-437, 2001.

DORST, Kees. The problem of Design Problems. In: DESIGN THINKING RESEARCH SYMPOSIUM, 6. Proceedings. Sydney: Sydney University of Technology, p. 135-147, 2003.

DORST, Kees. The Design Problem and its Structure. In: CROSS, N.; CHRISTIAANS, H.; DORST, K. (eds.). Analysing Design Activity. Chichester, UK: John Wiley and Sons Ltd., 1996, p. 17-34.

KAHNEMAN, D. Rápido e devagar: duas formas de pensar. Rio de Janeiro: Objetiva, 2012.

MAHER, M.; TANG, H. H. Co-evolution as a computational and cognitive model of design. Research in Engineering Design, vol. 14, p. 47-63, 2003.

MEYER, Guilherme Corrêa. Conflito, Negociação e Transformação: o Designer e o Processo de Desenvolvimento de Produto. Tese de Doutorado (Programa de PósGraduação em Design). Pontifícia Universidade Católica do Rio de Janeiro, Rio de Janeiro, 2010.

MORAES, Roque. Análise de Conteúdo. Revista Educação. Porto Alegre, n. 37, mar., 1999.

POON, J.; MAHER, M. L. Co-evolution and emergence in design. Artificial Intelligence in Engineering, vol.11, p. 319-327, 1997.

RITTEL, Horst W. J.; WEBBER, Melvin M. Dilemmas in a General Theory of Planning. Policy Sciences, Elsevier Scientific Publishing Company, Amsterdam, n. 4, 155-169, 1973.

SCHÖN, Donald A. Educando o profissional reflexivo. Porto Alegre: Artmed, 2000. SOUZA, Débora de Oliveira Lemos Rocha de Souza. A coevolução do problema de design. Dissertação (Programa de Pós-Graduação em Design). Universidade do Vale do Rio dos Sinos, Porto Alegre, 2015. 
TONETTO, L.; TAMMINEN, P. Understanding the role of intuition indecision-making when designing for experiences: contributions from cognitive psychology, Theoretical Issues in Ergonomics Science, 16:6, 631-642, 2015.

TVERSKY, A.; KAHNEMAN, D. Judgment under Uncertainty: Heuristics and Biases. Science, vol. 185, n. 4157, p. 1124-1131, 1974.

WILTSCHNIG, Stefan; CHRISTENSEN, Bo T; BALL, Linden J. Collaborative problemsolution co-evolution in creative design, Design Studies, vol. 24, p. 515-542, 2013. 